\title{
Hard X-ray Photoelectron Spectroscopy Study of Copper Formation by Metal Salt Inclusion in a Polymer Film
}

\author{
M. Snelgrove ${ }^{1 *}$, P. G. Mani-Gonzalez ${ }^{2,1}$, J. Bogan ${ }^{1}$, R. Lundy ${ }^{3}$, J.-P. Rueff ${ }^{4,5}$, G. Hughes ${ }^{1,6}$, P. \\ K. Yadav ${ }^{3}$, E. McGlynn ${ }^{1,6}$, M. Morris ${ }^{3}$, and R. O'Connor ${ }^{1}$ \\ ${ }^{1}$ School of Physical Sciences, Dublin City University, Glasnevin, Dublin 9, Ireland \\ 2Institute of Engineering and Technology, Department of Physics and Mathematics, Autonomous University of Ciudad Juarez, \\ Cd. Juarez 32310, Mexico \\ ${ }^{3} A M B E R$, Trinity College Dublin, College Green, Dublin 2, Ireland \\ ${ }^{4}$ Synchrotron SOLEIL L'Orme des Merisiers, BP 48 Saint-Aubin, 91192 Gif-sur-Yvette, France \\ ${ }^{5}$ Sorbonne Université, CNRS, Laboratoire de Chimie Physique - Matiére et Rayonnement, LCPMR, F-75005 Paris, France \\ ${ }^{6}$ National Centre for Plasma Science and Technology, Dublin City University, Glasnevin, Dublin 9, Ireland
}

\begin{abstract}
In this work we present the results of a Hard X-ray Photoelectron Spectroscopy (HAXPES) study on the creation of metallic copper layers via metal-salt infiltration into a poly-2-vinylpyridine (P2VP) film. Metal salt inclusion is a wet chemistry process which allows for the fabrication of both metal and metal oxide films by means of infiltrating a receptive polymer thin film with metal salt precursors. A copper infiltrated P2VP film was subject to UV/Ozone treatment to form copper oxide and annealed in-vacuo to reduce the film to metallic copper. HAXPES and transmission electron microscope (TEM) measurements were used to study the polymer film before and after metal salt infiltration, along with analysis of the copper oxide created after UV/Ozone treatment. The results show successful infiltration of the metal salt into the polymer film, as well as complete conversion to copper oxide following UV/Ozone treatment and reduction to metallic copper with a subsequent in-situ anneal, which demonstrates the ability of the technique for the creation of several key integrated circuit features.
\end{abstract}

Keywords: Polymer Infiltration; Area Selective Deposition; P2VP; Metal Salt; HAXPES

\section{Introduction}

It is recognised that the lithographic processes that underpin the fabrication of advanced microelectronic devices are approaching their limit in terms of size and cost in the semiconductor industry ${ }^{1}$. For upcoming CMOS processes which will be based on sub $7 \mathrm{~nm}$ feature sizes, alternative methods of pattern formation are being investigated. One such approach known as Area Selective Deposition (ASD), is a non-lithographic, 'bottom-up' patterning technique which relies on the activation or de-activation of surfaces so as to promote or inhibit material growth on those surfaces, respectively. Such a design architecture

${ }^{*}$ Corresponding Author 
would allow for fewer lithography and etching steps as well as a reduction in alignment problems inherent to optical lithography, such as edge-placement errors.

A particularly interesting ASD methodology is to combine the concept with a self-assembly process that allows simultaneous development of active and deactivated areas of a substrate. One such technique is the use of block copolymers (BCPs) ${ }^{2}$. BCPs contain dissimilar, covalently bonded polymer blocks, that exhibit microphase separation (self-assembly) into a range of morphologies, forming patterns that have potential use for 2D and 3D fabrication processes 3,4 . By implementing these different morphologies, it is anticipated that BCPs can be used to create a large array of future nanoelectronic devices. Recent studies on BCPs have shown that nanoscale features can be developed - as illustrated by the work of Borah et al. who have successfully implemented ion etching onto self-assembled polystyrene-b-poly(methyl methacrylate) (PS-bPMMA) BCP patterns, thereby producing PS nanowires with the removal of the PMMA block 5 . PS-b-PMMA has also been used to create $\mathrm{Al}_{2} \mathrm{O}_{3}$ nanofeatures ${ }^{6}$, along with $\mathrm{ZnO}$ and $\mathrm{TiO}_{2}$ nanopatterns ${ }^{7}$. Work by Cummins et al. resulted in the creation of $\mathrm{WO}_{3}$ nanowires by implementing a poly(styrene)-block-poly(4-vinylpyridine) (PS-b-P4VP) template ${ }^{8}$, while self-assembled polystyrene-block-poly(ethyleneoxide) (PS-b-PEO) has been used to create lead zirconate titanate (PZT) nanodots by means of PEO infiltration ${ }^{9}$.

Ultimately, in order to develop a scalable and manufacturable process, the goal of BCP processes is to have infiltration by an atomic layer deposition (ALD) process into the acceptor material with blocking of the ALD growth, or at least blocking of the infiltration, by the rejecting material. In this work we employ a metal salt inclusion technique as a simple controllable infiltration method, using a copper nitrate salt, in order to understand the basic infiltration chemistry which will underpin these processes. Metal salt inclusion involves exposing a BCP sample to a metal salt precursor of interest in solution form. The solvent will either infiltrate or swell on the polymer it has come into contact with, meaning the polymers in the sample can be segregated into 'acceptors' or 'rejectors' of the metal salt solution. BCPs can be fabricated so that there are acceptor and rejector sites on a given BCP sample ${ }^{10}$, which means subsequent removal of the polymers allows for the potential creation of both metals and metal oxides, patterned in such a way that imitates the original morphology of the BCP to which the solvent was exposed.

The focus of this work is on the Hard X-ray Photoelectron Spectroscopy (HAXPES) chemical characterisation of the infiltration process into an 'active' material - the creation of metallic copper via the metal salt inclusion technique. Hydroxy-terminated poly-2-vinylpyridine (P2VP$\mathrm{OH})$, which is a polymer material that has the potential to be used as an acceptor in block copolymer processes ${ }^{11,12}$, was formed into thin films and subsequently infiltrated with copper salt (the 'Cu Salt' sample), with the sample then being oxidized ('Cu Oxide') and finally annealed in a reducing environment ('Salt Anneal' and 'Oxide Anneal'). The summary of this idealised experimental methodology is shown in figure 1. Each stage of the fabrication process was chemically analysed using HAXPES measurements, from the fabricated 'acceptor' polymer to the metallic copper created via the process. The significantly larger sampling depth of this spectroscopic measurement technique $(<30 \mathrm{~nm})$, compared to conventional XPS $(<7-8 \mathrm{~nm})$ means that the complete film thickness can be investigated and localised surface contamination does not dominate the spectral analysis. 


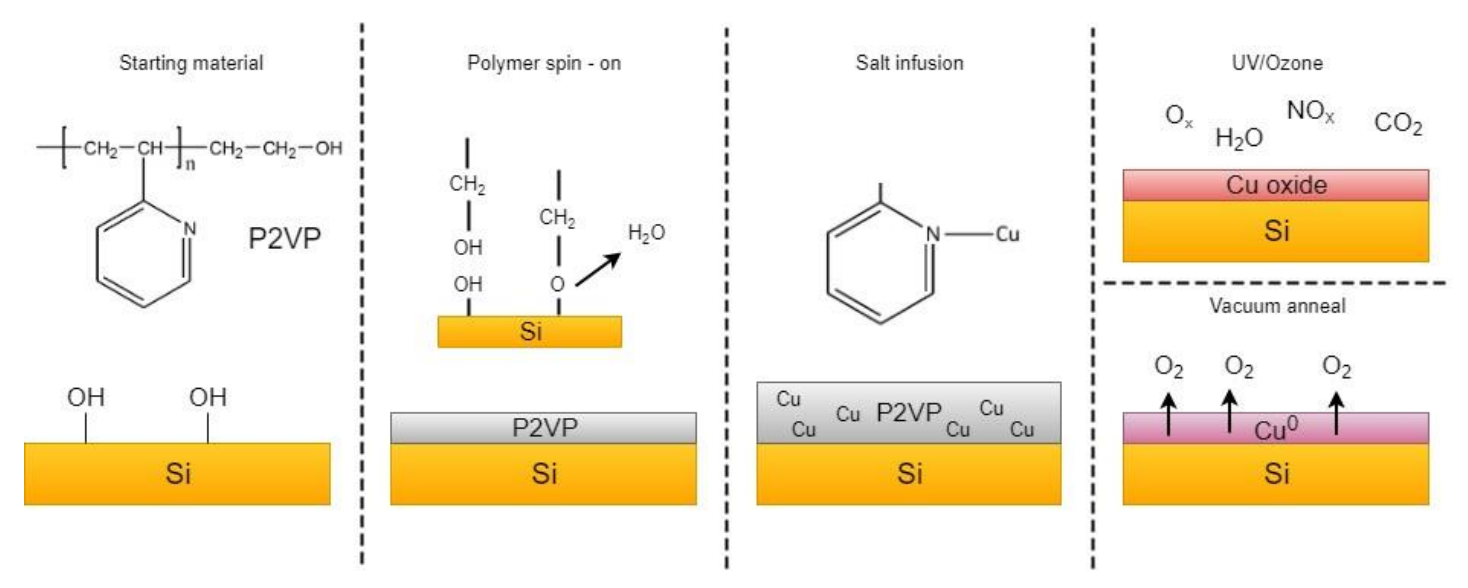

Fig. 1: Schematic diagram showing the idealised process to fabricate a metallic Cu film. Starting with the hydroxide terminated Si, the spun on polymer layer reacts with the surface to form a covalently bonded thin film of P2VP. Metal salt inclusion results in the incorporation of the copper into the film. A subsequent oxidation step removes the polymer host and oxidises the metal and finally a thermal anneal in vacuum reduces the metal oxide to form a metallic copper film.

\section{Experimental Details}

\section{Materials}

Blanket silicon with native oxide was provided by collaborators (Intel). The polymer, hydroxyterminated poly-2-vinylpyridine $(\mathrm{P} 2 \mathrm{VP}-\mathrm{OH})\left(\mathrm{Mw}=6.2 \mathrm{~kg} \mathrm{~mol}^{-1}, \mathrm{PDI}=1.05\right)$ was purchased from Polymer Source Inc. Canada and used as received. Copper(II) nitrate hydrate $\left(\mathrm{Cu}\left(\mathrm{NO}_{3}\right)_{2} \cdot \mathrm{XH}_{2} \mathrm{O}\right.$, 99.999\%), Ethanol (anhydrous, for HPLC $\geq 99.9 \%$ ) and Tetrahydrofuran (inhibitor-free, CHROMASOLV Plus, for HPLC, $\geq 99.9 \%)$, was purchased from Sigma Aldrich and used as received. Deionized water (resistivity $=18.2 \mathrm{M} \Omega \cdot \mathrm{cm}$ ) was used were necessary.

\section{Surface cleaning and polymer deposition}

Substrates were cleaved into $2 \times 2 \mathrm{~cm}^{2}$ pieces and ultrasonicated in THF for 20 mins to remove any silicon dust. Silicon substrates were hydroxyl functionalised using piranha solution $(1: 3 \mathrm{v} / \mathrm{v}$ $30 \% \mathrm{H}_{2} \mathrm{O}_{2}: \mathrm{H}_{2} \mathrm{SO}_{4}$ ) at $100^{\circ} \mathrm{C}$ for 60 min and thoroughly rinsed in DI water and dried under $\mathrm{N} 2$ gas. The $\mathrm{P} 2 \mathrm{VP}-\mathrm{OH}$ polymer was dissolved in tetrahydrofuran (THF) by stirring overnight at room temperature to yield a $0.2 \mathrm{wt} \%$ polymer solution and spin coated at $3000 \mathrm{rpm}$ for 30 seconds. Samples were immediately placed in a vacuum oven and baked for $30 \mathrm{~min}$ at $190^{\circ} \mathrm{C}$. Following this samples were sonicated in THF for a total of 30 mins ( $3 \times 10$ mins washes). This was carried out to remove physiosorbed ungrafted polymer material and produce monolayer coverage. Copper salt solutions ( $0.5 \mathrm{wt} . \%$ in ethanol) were spin coated (3000 rpm/30s) onto to the grafted films. Conversion to oxide and polymer ashing was performed by exposing to UV/Ozone for 3 hr. (Novascan PDSP-UV4).

\section{Characterisation}

Hard X-ray photoelectron spectroscopy analysis was performed at the SOLEIL Synchrotron at the Galaxies Beamline ${ }^{13}$. Spectra were acquired at pressures of $1 \times 10^{-9} \mathrm{mbar}$ with photon beam energies of $3 \mathrm{keV}$ and $10 \mathrm{keV}$, which allows for probing of deep core levels of all elements 
present, as well as the acquisition of more bulk sensitive (10 keV) and more surface sensitive (3 $\mathrm{keV})$ spectra. $\mathrm{Si}(111)$ and $\mathrm{Si}(333)$ monochromators were used for the $3 \mathrm{keV}$ and $10 \mathrm{keV}$ beams respectively. The effect of an in-situ anneal on both infiltrated salt and UV/Ozone treated polymer samples was also investigated. All anneals were performed at a temperature of $400^{\circ} \mathrm{C}$ for 30 minutes in the preparation chamber (adjacent to the analysis chamber) with a base pressure of $1 \times 10^{-9} \mathrm{mbar}$.

All peak fitting analysis of the HAXPES spectra was performed using the AAnalyzer software ${ }^{14}$. The spectra were fitted by using a Voigt function, and the Gaussian and Lorentzian values for each core level are tabulated in table 1. Each core level was assigned a single Gaussian and Lorentzian value for all its components, with the exceptions being one component in the $01 \mathrm{~s}$ and several components in the $\mathrm{Cu}$ core levels, due to significant differences in the chemical environment. Shirley-type and slope backgrounds were used for all the core levels, with the exception of the $\mathrm{Cu} 2 p$, where a static Shirley background was implemented. The spectra were not normalised, however an offset was applied so that the background of each photoemission plot occurred at 0 intensity (counts).

Sample preparation for the transmission electron microscope (TEM) was performed in a FEI Helios Nanolab 450 S. Substrates were imaged to locate a clean, defect free area. This area was subsequently platinum capped. Pt was deposited via a gas injection system (GIS) technique. Low accelerating voltage was used to construct a protective layer, initially a $500 \mathrm{~V}$ electron beam was used to deposit Pt, thereafter a $2 \mathrm{kV}$ and finally a $30 \mathrm{kV}$ ion beam. Cross section lamella were lifted out using standard focused ion beam procedures. This lamella was platinum welded to the molybdenum grid and stored in a vacuum sample holder prior to TEM imaging. TEM imaging was performed in a FEI OSIRIS TEM. All imaging was performed at $200 \mathrm{kV}$. Both Brightfield and scanning transmission electron microscope (STEM) modes were used. For STEM imaging, detector lengths of 220, 550 and $770 \mathrm{~mm}$ were used. Energy dispersive X-ray spectroscopy (EDX) mapping was used to perform elemental analysis of samples. All EDX maps were acquired during a sampling duration of 20 minutes. 


\begin{tabular}{lllllll}
\hline $\begin{array}{l}\text { Core Level } \\
\text { Peak }\end{array}$ & $\begin{array}{l}\text { Chemical } \\
\text { Environment }\end{array}$ & $\begin{array}{l}\boldsymbol{h v} \\
(\mathrm{eV})\end{array}$ & $\begin{array}{l}\text { Spin Orbit } \\
\text { Splitting }(\mathrm{eV})\end{array}$ & $\begin{array}{l}\text { Gaussian } \\
(\mathrm{eV})\end{array}$ & $\begin{array}{l}\text { Lorentzian } \\
(\mathrm{eV})\end{array}$ & $\begin{array}{l}\text { Binding } \\
\text { Energy (eV) }\end{array}$ \\
\hline $\mathrm{Si} 2 p$ & Bulk & 3000 & 0.6 & - & - & 99.4 \\
$\mathrm{C} 1 s$ & Pyridine & 3000 & - & 1.11 & 0.27 & 285.7 \\
$\mathrm{~N} 1 s$ & Pyridine & 3000 & - & 1.13 & 0.51 & 399.8 \\
$\mathrm{O} 1 \mathrm{~s}$ & $\mathrm{P} 2 \mathrm{VP} / \mathrm{SiO}_{2}$ & 3000 & - & 1.13 & 0.25 & 532.6 \\
$\mathrm{O} 1 s$ & $\mathrm{Cu}^{0}$ & 3000 & - & 0.58 & 0.25 & 530.2 \\
$\mathrm{Cu} 2 p$ & $\mathrm{Cu}^{2+}$ & 3000 & 19.7 & 1.28 & 0.05 & 934.5 \\
$\mathrm{Cu} 2 p$ & $\mathrm{Cu}^{1+}$ & 3000 & 19.7 & 1.28 & 0.05 & 933.4 \\
$\mathrm{Cu} 2 p$ & $\mathrm{Cu}^{0}$ & 3000 & 19.7 & 0.84 & 0.05 & 932.4 \\
$\mathrm{Cu} 1 s$ & $\mathrm{Cu}^{2+}$ & 10000 & - & 2.58 & 1.04 & 8982.4 \\
$\mathrm{Cu} 1 s$ & $\mathrm{Cu}^{1+}$ & 10000 & - & 1.46 & 1.04 & 8981.1 \\
$\mathrm{Cu} 1 s$ & $\mathrm{Cu}^{0}$ & 10000 & - & 1.48 & 1.04 & 8979.9 \\
\hline
\end{tabular}

Table. 1: AAnalyzer Gaussian and Lorentzian values used.

\section{Results and Discussion}

\section{P2VP Film}

Wide energy range survey scans of the P2VP thin films were undertaken using a photon beam energy of $3 \mathrm{keV}$, and $\mathrm{C} 1 \mathrm{~s}, \mathrm{~N} 1 \mathrm{~s}, \mathrm{O}$ 1s and Si $2 p$ signals were acquired. Figure $2 a$ shows the Si $2 p$ signal for all experimental steps, which consists of two photoemission components separated by an energy $(\Delta \mathrm{E})$ of $3.9 \mathrm{eV}$.

The lower binding energy component represents $\mathrm{Si}^{0}$ (silicon bulk), while the higher binding energy peak represents $\mathrm{Si}^{4+}\left(\mathrm{SiO}_{2}\right)$, attributed to the native silicon oxide substrate onto which the polymer was grafted ${ }^{15}$. All spectra were adjusted for charging such that the position of the $2 p_{3 / 2}$ bulk component was fixed at $99.4 \mathrm{eV}^{16,17}$. This compensation was applied to all core levels in this work.

The signal is dominated by the Si bulk signal due to the large sampling depth of the $3 \mathrm{keV}$ photon beam, however $\mathrm{SiO}_{2}$ is evident clearly at $103.3 \mathrm{eV}$. There is also evidence of low concentrations of $\mathrm{Si}^{3+}, \mathrm{Si}^{2+}$ and $\mathrm{Si}^{1+}$ signals in the spectra, representing sub-stoichiometric silicon oxides at the interface between the oxide and the silicon bulk and where the polymer grafts to the $\mathrm{SiO}_{2}$ layer.

The $\mathrm{O} 1 \mathrm{~s}$ in figure $2 \mathrm{~b}$ for the $\mathrm{P} 2 \mathrm{VP}$ is dominated by $\mathrm{C}-\mathrm{O}$ and $\mathrm{SiO}_{2}$ bonds, occurring at $533.2 \mathrm{eV}$ and $532.6 \mathrm{eV}$, respectively ${ }^{18-21}$. The minor peak at $531.8 \mathrm{eV}$ resembles carbon oxygen bonds arising from atmosphere exposure as were seen in figure $3 a$.

The $C 1 s$ spectra for each experimental step $(h v=3 \mathrm{keV})$ are shown in figure 3a. The P2VP signal contains $\mathrm{C}-\mathrm{C}$ bonds at $285.0 \mathrm{eV}^{22-24}$, which are associated with the carbon chain in the polymer. The signal at $285.7 \mathrm{eV}$ is reported as the carbon component of the pyridine ring ${ }^{25,26}$. The $\mathrm{C} 1 \mathrm{~s}$ signal for the P2VP is dominated by this (C-Pyridine) component. The peaks at $286.5 \mathrm{eV}$ and $287.6 \mathrm{eV}$ are associated with $\mathrm{C}-\mathrm{O}$ and $\mathrm{C}=\mathrm{O}$ bonds respectively, while the final peak at $288.7 \mathrm{eV}$ is attributed to carboxyl groups $(\mathrm{O}-\mathrm{C}=\mathrm{O})$, based on reports in the literature $22,24,27$. The $\mathrm{C}-\mathrm{O}$ bonds are attributed to carbon oxygen bonds arising from the interface where the polymer bonds to the $\mathrm{SiO}_{2}$, as well as contributions from the top surface oxidation due to atmosphere exposure. The other $\mathrm{O}$ components in the spectra $(\mathrm{C}=\mathrm{O}$ and $\mathrm{O}-\mathrm{C}=\mathrm{O})$ can also be attributed to this top layer. 
Figure $3 \mathrm{~b}$ shows the spectra and fit of the $\mathrm{N} 1 \mathrm{~s}$ for the polymer pre- and post-infiltration as well as post-UV/Ozone treatment. For the as-deposited P2VP, three component peaks are apparent, with the major component located at $399.8 \mathrm{eV}$. However trace signals are also found at 400.9 $\mathrm{eV}$ and $406.8 \mathrm{eV}$. The peak at $399.8 \mathrm{eV}$ is attributed to pyridinic ( $\mathrm{C}-\mathrm{N}=\mathrm{C})$ nitrogen, while the component at $400.9 \mathrm{eV}$ is attributed to $\mathrm{C}-\mathrm{NH}-\mathrm{C}$ bonds, associated with pyrrolic nitrogen ${ }^{28,29}$. The small component at $406.8 \mathrm{eV}$ is associated with physisorbed nitrogen ${ }^{29}$.

EDX mapping data acquired from transmission electron microscopy (TEM) images of the P2VP film are shown in figure 4. C, N, O and F signal data are shown. F is used to detect the platinum resist, which is placed on top of the polymer sample before the EDX analysis. The images show that a thin, uniform film composed of $\mathrm{O}, \mathrm{C}$ and $\mathrm{N}$ exists above the silicon bulk.
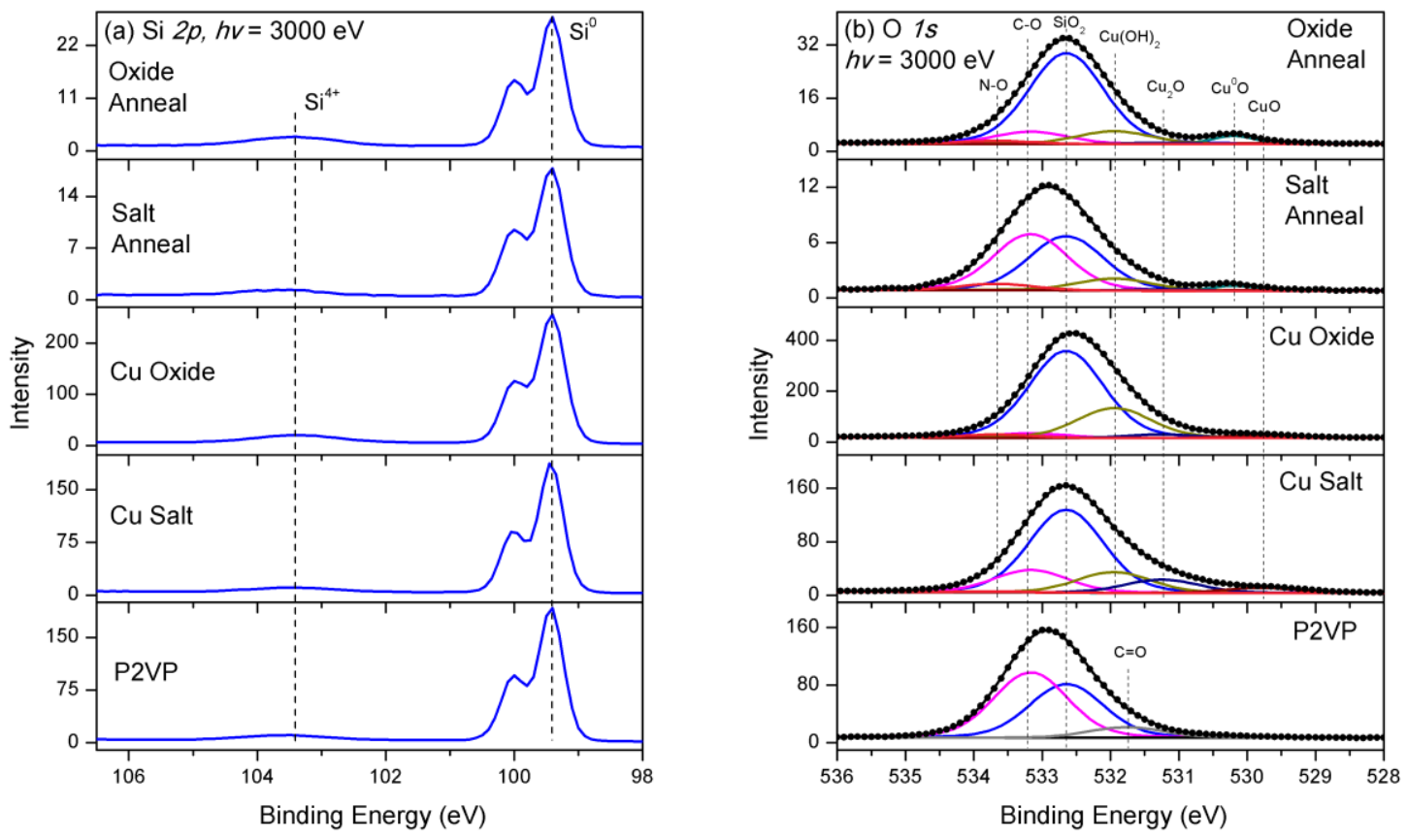

Fig. 2: (a) Si $2 p$ peak data at $h v=3 \mathrm{keV}$ for all the experimental steps. The data has been shifted so that the bulk signal occurs at $99.4 \mathrm{eV}$. The composition of each peak remains unchanged throughout all the samples analysed, however the counts are reduced significantly after both anneal steps (associated with the formation of metallic copper). (b) Fit of the $O 1 \mathrm{~s}$ peak for all the experimental steps. A significant shoulder develops on the spectra at the lower binding energies after the infiltration step, attributed to the copper oxide components.

\section{P2VP with Cu Salt Infiltration}

XPS survey scans of the 'Cu salt' samples reveal peaks associated with $\mathrm{Cu}$ in addition to the polymer and $\mathrm{Si}$ components, indicating that the process has incorporated $\mathrm{Cu}$ into the polymer. The presence of $\mathrm{Cu}$ is also confirmed by EDX analysis, discussed below. Spectra for the infiltrated polymer samples were acquired at $h v=3 \mathrm{keV}$. The $\mathrm{Cu} 1 \mathrm{~s}$ spectrum was also obtained, using a photon beam energy of $10 \mathrm{keV}$. 

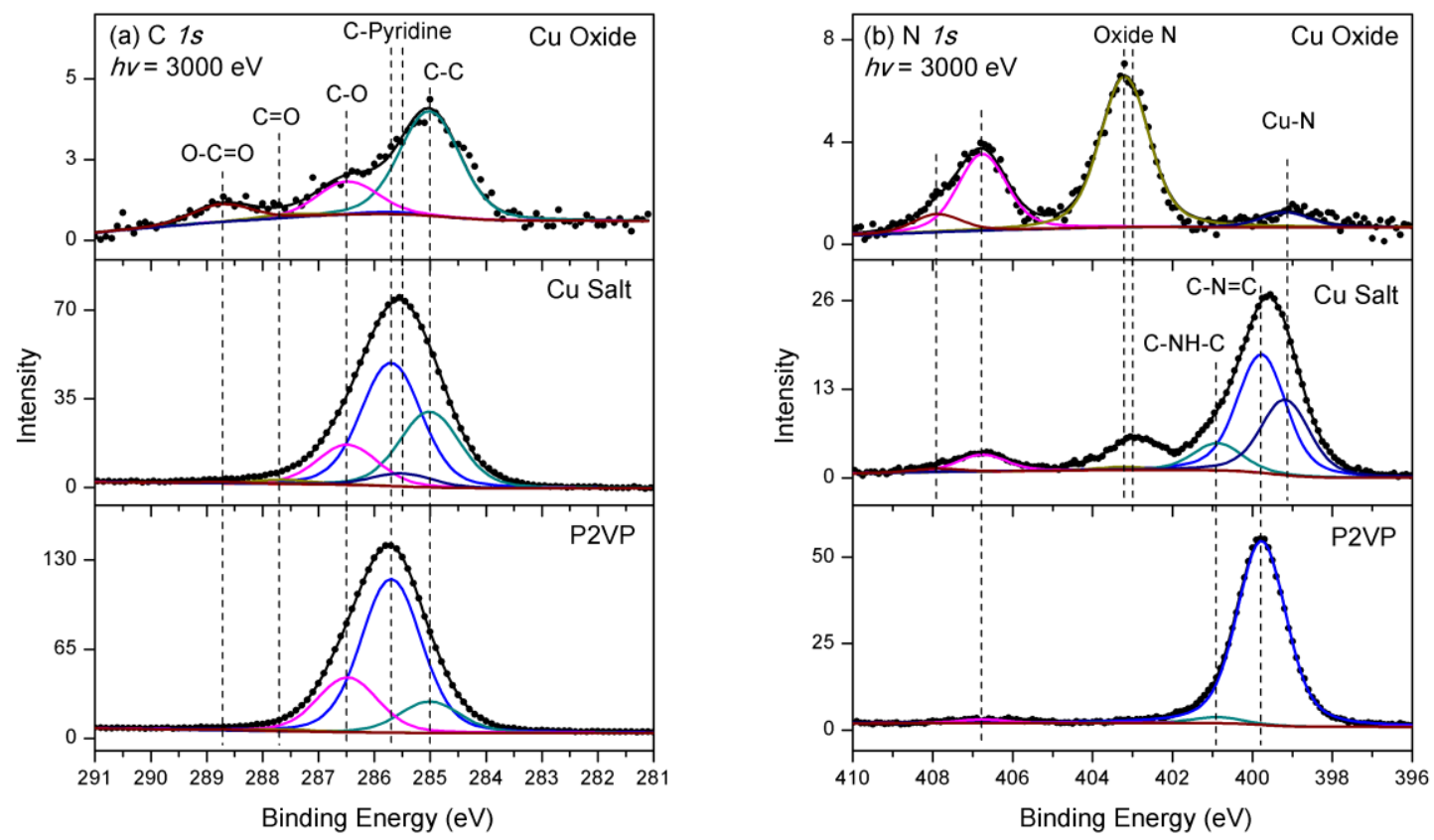

Fig. 3: (a) C 1s core level fit for the polymer pre and post infiltration. C-Pyridine bonds dominate the P2VP, while being almost completely removed after the oxidation step. (b) Fit of the $N$ 1s peak for the polymer, salt and copper oxide. A lower binding energy component is attributed to Cu interaction with the pyridinic $N$ after the infiltration step. A small signal attributed to oxidised nitrogen is the only significant remainder of the element after the UV/Ozone treatment. Physisorbed nitrogen is also evident with the addition of a higher binding energy component.

The Si $2 p$ spectrum (figure $2 a$ ) for the Cu salt sample reveals little has changed in the profile of the peak, showing that the $\mathrm{Cu}$ salt has not chemically interacted with the silicon substrate or native oxide layer.

The $\mathrm{O} 1 \mathrm{~s}$ spectrum (figure $2 \mathrm{~b}$ ) undergoes a significant change in profile after the infiltration step, which is explained by the addition of peak components attributed to oxidised copper bonds, with $\mathrm{Cu}(\mathrm{OH})_{2}, \mathrm{Cu}_{2} \mathrm{O}$ and $\mathrm{CuO}$ identified at $531.9 \mathrm{eV}, 531.2 \mathrm{eV}$ and $529.8 \mathrm{eV}$ respectively, similar to what has been reported by Biesinger and others ${ }^{30,31} \cdot \mathrm{SiO}_{2}$ is the most prominent component, with the surface $\mathrm{C}-\mathrm{O}$ bonds decreasing in intensity due to the introduction of the metal salt.

Once the infiltration step has been completed, the profile of the C 1s (figure 3a) undergoes some changes. The peak maxima experiences a shift, resulting in the addition of a component at $285.5 \mathrm{eV}, 0.2 \mathrm{eV}$ lower in binding energy when compared to the C-pyridine peak at $285.7 \mathrm{eV}$. This is expected, as there is a strong interaction between the infiltrated $\mathrm{Cu}$ and the $\mathrm{N}$ in the pyridine ring as seen in figure $3 b, 5 a$ and $5 b^{32,33}$.

The infiltration step causes a shift in the maximum peak position of the $\mathrm{N} 1 \mathrm{~s}$ signal (figure $3 \mathrm{~b}$ ). This is caused by a new component in the peak profile at a lower binding energy than the pyridinic $\mathrm{N}$. This peak is attributed to $\mathrm{Cu}-\mathrm{N}$ bonds, and it is centred around $399.2 \mathrm{eV}$, at a binding 
energy of $0.6 \mathrm{eV}$ lower than the $\mathrm{C}-\mathrm{N}=\mathrm{C}$ bonds ${ }^{34-36}$. A small peak located at $403.2 \mathrm{eV}$ is assigned to oxidised nitrogen ${ }^{29,37}$.

The $\mathrm{Cu} 2 p_{3 / 2}$ spectra can be deconvoluted into their constituent components as shown in figure 5a. The salt-infiltrated sample has major components at 933.4, 934.5, 935.6 and $934.2 \mathrm{eV}$, with the first three representing $\mathrm{Cu}^{1+}, \mathrm{Cu}^{2+}, \mathrm{Cu}(\mathrm{OH})_{2}$ respectively ${ }^{30}$, while the latter is attributed to $\mathrm{Cu}-\mathrm{N}$ bonds. A sub oxide component $(\mathrm{CuOH})$ attributed to the environment is located at 936.7 $\mathrm{eV}$, while a component at $932.1 \mathrm{eV}$ was also added to the fit. Unattributed low binding energy features have been observed in a variety of core levels from XPS analysis ${ }^{38-40}$, and it is possible that this feature has arisen from surface defects arising from strains in the film ${ }^{41,42}$. A small peak at $932.4 \mathrm{eV}$ was associated with metallic copper $\left(\mathrm{Cu}^{0}\right)$. The components at 937.7, 940.4, 941.9 and $943.7 \mathrm{eV}$ were associated with shake up satellite features for each Cu oxidation state for the $\mathrm{Cu} 2 p^{30}$. Therefore the salt-infiltrated film consists of $\mathrm{Cu}$ in a number of oxidation states, including $\mathrm{Cu}(\mathrm{OH})_{2}$ as well as $\mathrm{CuOH}$, with the most prominent being $\mathrm{Cu}^{1+}$, which is associated with copper bonding to nitrogen and oxygen in the film.

The Cu $1 \mathrm{~s} \mathrm{spectra,} \mathrm{acquired} \mathrm{at} h v=10 \mathrm{keV}$, and shown in figure $5 \mathrm{~b}$, is correlated with the $\mathrm{Cu} 2 p$ fit. Peaks at $8979.9,8981.1$ and $8982.0 \mathrm{eV}$ are attributed to $\mathrm{Cu}^{0}, \mathrm{Cu}^{1+}$ and $\mathrm{Cu}-\mathrm{N}$ bonds. $\mathrm{Cu}(\mathrm{OH})_{2}$ can also be seen at $8984.4 \mathrm{eV}$, while the components at around $8989.5 \mathrm{eV}$ are attributed to satellite features. Consistent with the $\mathrm{Cu} 2 p$ data in figure $5 \mathrm{a}$, the most prominent oxidation state appears to be $\mathrm{Cu}^{1+}$.

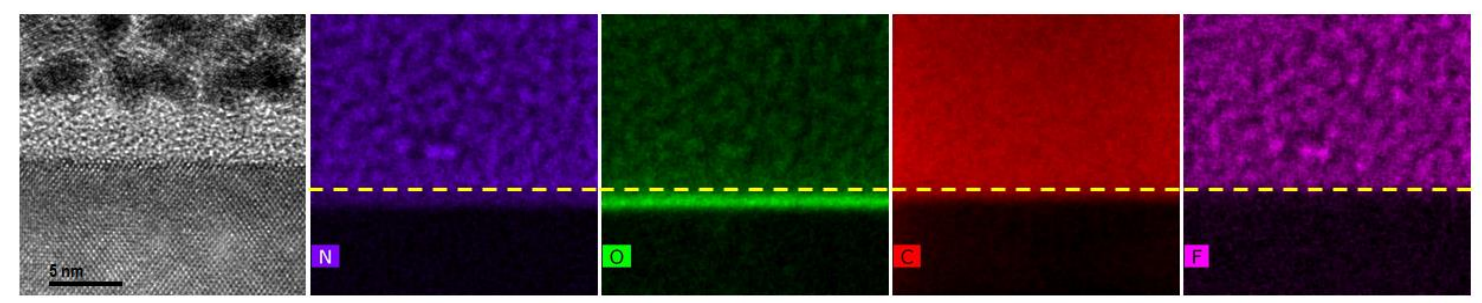

Fig. 4: EDX mapping data by TEM of the P2VP layer, showing nitrogen, oxygen and carbon present in a thin layer on top of silicon (not shown). The yellow line indicates where the polymer ends and the platinum resist begins. This was observed by detecting fluorine in the resist.

\section{Post UV/Ozone treatment}

The copper oxide samples (labelled as ' $\mathrm{Cu}$ Oxide' in the relevant figures) prepared via a three hour UV/Ozone treatment were analysed in a similar manner to the Cu salt samples, with $h v=$ $3 \mathrm{keV}$ spectra obtained for the Si $2 p, \mathrm{C} 1 s, \mathrm{~N} 1 \mathrm{~s}, \mathrm{O} 1 \mathrm{~s}$ and $\mathrm{Cu} 2 p$ peaks, along with $h v=10 \mathrm{keV}$ spectra of the $\mathrm{Cu} 1 \mathrm{~s}$. The $\mathrm{Si} 2 p$ spectrum in figure $2 \mathrm{a}$ remains unchanged in profile following the UV/Ozone treatment.

The $\mathrm{O} 1 \mathrm{~s}$ (figure $2 \mathrm{~b}$ ) spectra for the copper oxide sample is similar to the $\mathrm{Cu}$ salt sample, however there is an increase in the intensity of the signal. There is a reduction in $\mathrm{C}-\mathrm{O}$ bonds, correlating with the $\mathrm{C} 1 \mathrm{~s}$ spectra, while the $\mathrm{SiO}_{2}, \mathrm{Cu}(\mathrm{OH})_{2}$ and $\mathrm{CuO}$ components increase. The oxidation state of the copper changes during the treatment, as there is an increase in $\mathrm{CuO}$ and a decrease in $\mathrm{Cu}_{2} \mathrm{O}$ after the UV/Ozone treatment, consistent with 

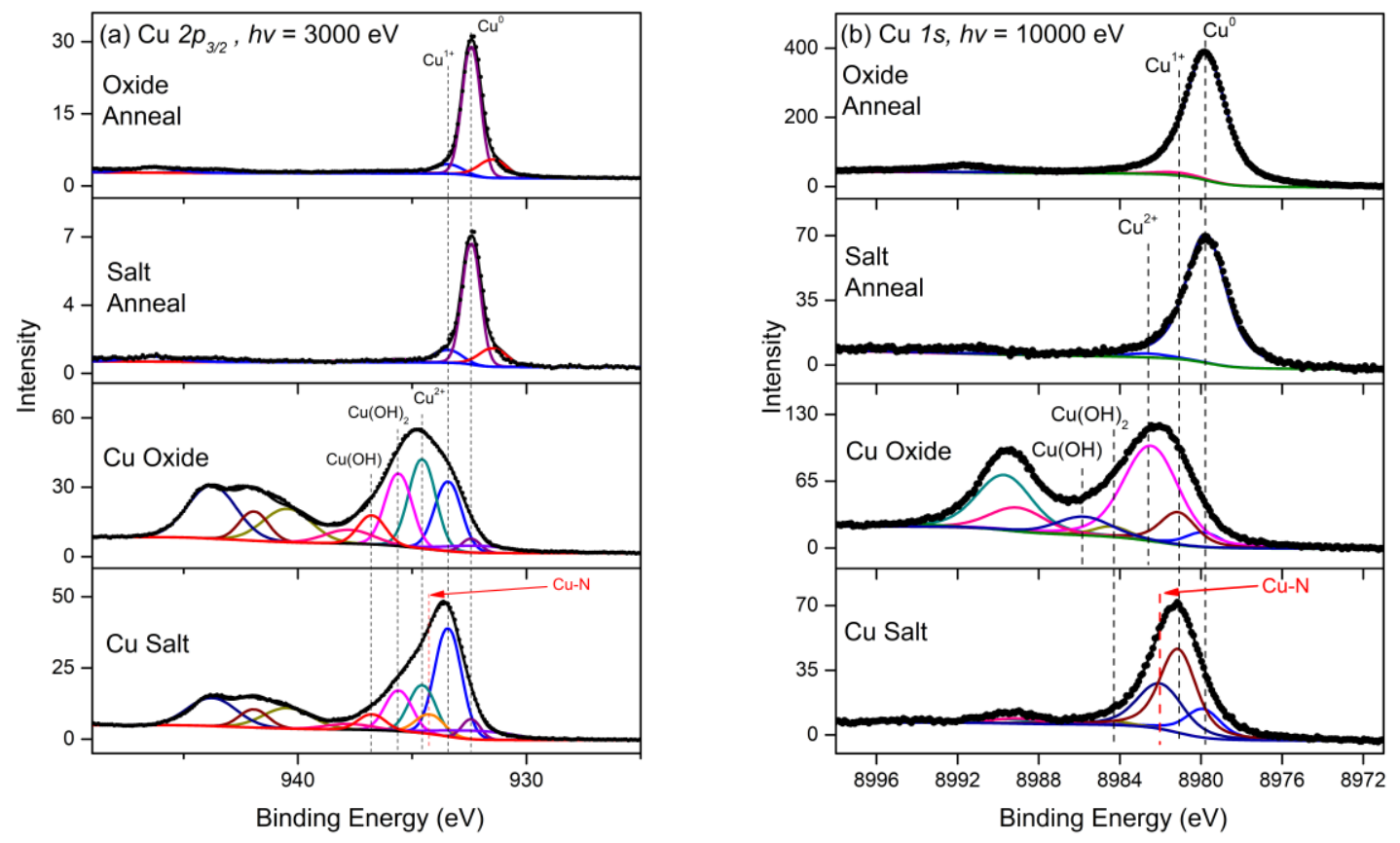

Fig. 5: (a) XPS spectra of $\mathrm{Cu} 2 p_{3 / 2}, h v=3 \mathrm{keV}$. The spectra for the infiltrated salt sample shows a strong $\mathrm{Cu}^{1+}$ contribution, while the subsequent UV/Ozone treatment results in $\mathrm{Cu}^{2+}$ becoming the most significant component. Annealing both these samples results in the formation of a film dominated by a metallic $\mathrm{Cu}^{0}$ contribution. The metallic signal is significantly stronger on the annealed, UV/Ozone sample. (b) XPS spectra of $\mathrm{Cu} 1 \mathrm{~s}, \mathrm{hv}=10 \mathrm{keV}$, which are broadly consistent with the $\mathrm{Cu} 2 p_{3 / 2}$ data in (a). The intensities of the spectra are not normalised to any reference, however an offset has been applied so that the background of each plot occurs at 0 intensity.

the Cu peak fit in figure $5 \mathrm{a}$ and $5 \mathrm{~b}$.

The oxidation step reveals a noisy $C 1$ s spectrum (figure $3 a$ ), with $C-C$ bonds representing the majority of the peak profile. The reduction of the C-pyridine signals correlates with the $\mathrm{N} 1 \mathrm{~s}$ spectra in figure $3 \mathrm{~b}$. C-O bonds remain, and are attributed to the surface of the material due to atmosphere exposure.

In the $\mathrm{N}$ 1s spectrum (figure $3 \mathrm{~b}$ ) the oxidation step leaves only trace $\mathrm{Cu}-\mathrm{N}$ bonds, while the oxidised nitrogen peak becomes the most prominent. The $\mathrm{C}-\mathrm{N}=\mathrm{C}$ bonds are no longer visible, indicating that UV/Ozone treatment has successfully removed the P2VP.

The $\mathrm{Cu} 2 p_{3 / 2}$ spectrum in figure 5 a for the copper oxide sample is similar to the copper salt profile, with a few notable differences. The $\mathrm{Cu}-\mathrm{N}$ component that was observed in the salt at $934.2 \mathrm{eV}$ is no longer present, consistent with the $\mathrm{N} 1 \mathrm{~s}$ spectra. There is also a change in the most prevalent oxidation state of the $\mathrm{Cu}$ signal, as the most intense oxidation state of copper transitions from $\mathrm{Cu}^{1+}$ to $\mathrm{Cu}^{2+}$, correlating with the $\mathrm{O} 1 \mathrm{~s}$ peak. It can therefore be concluded that, before the oxidation step, the spun on copper salt solution exists in the polymer film in a mixed oxidation state, with $\mathrm{Cu}^{1+}$ being the most prominent. After UV/Ozone treatment however, the 
copper nitrogen bonds are removed, and the overall oxidation of the of the copper becomes dominated by $\mathrm{Cu}^{2+}$ and to a lesser extent, $\mathrm{Cu}(\mathrm{OH})_{2}$.

The differences between the salt and oxide samples are even clearer in the $\mathrm{Cu} 1 \mathrm{~s}$ spectra, with the major component now being $\mathrm{Cu}^{2+}$ instead of $\mathrm{Cu}^{1+}$ as discussed above in the $\mathrm{Cu} 2 p$ spectra, with the increase in $\mathrm{Cu}(\mathrm{OH})_{2}$ also correlating with the $\mathrm{Cu} 2 p$ fit. The oxidized $\mathrm{Cu}$ signal is significantly more intense here, with the two satellite features also being major components now due to the increase in $\mathrm{Cu}^{2+}$.

EDX mapping data of the copper oxide sample supports these conclusions from the XPS data, showing a thin layer containing $\mathrm{Cu}$ and $\mathrm{O}$ on top of a $\mathrm{SiO}_{2}$ thin layer. The film is incomplete in regions, as shown in figure $6 \mathrm{~b}$, highlighting the need for further work to perfect the fabrication process to achieve continuous films.
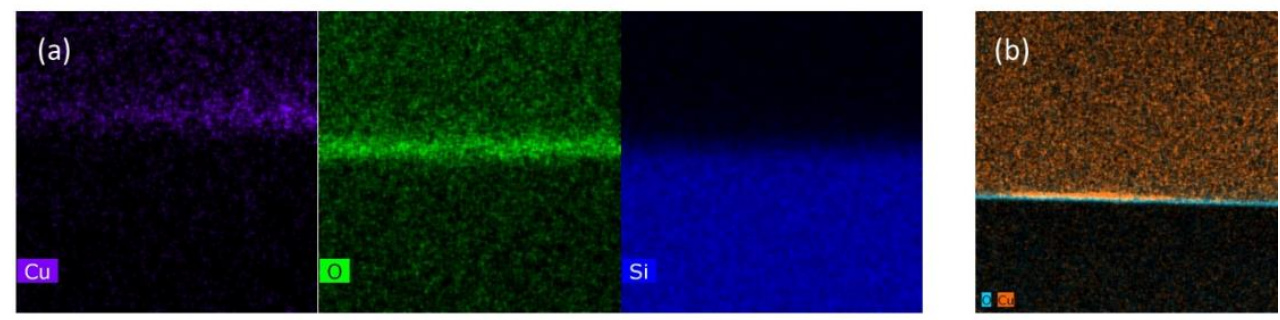

Fig. 6: (a) EDX mapping data from TEM measurements of the polymer film infiltrated by the Cu salt sample which display evidence of the incorporation of $\mathrm{Cu}$ into the film in a thin layer above the $\mathrm{SiO}_{2}$. (b) EDX overlaid image of copper and oxygen for the UV/Ozone treated sample. The result shows the successful formation of copper oxide on the surface, however the layer is uneven and not continuous across the surface.

\section{Reductive Anneals}

It was outlined previously that both the $\mathrm{Cu}$ salt and the $\mathrm{Cu}$ Oxide samples were annealed at $400^{\circ} \mathrm{C}$ for 30 minutes (labelled 'salt anneal' and 'oxide anneal', respectively). The Si $2 p$ spectrum (figure 2a) shows a notable drop in signal after the annealing step of both the annealed saltinfiltrated and oxide samples when comparing it to the pre-anneal copper oxide spectrum (as well as the $\mathrm{Cu}$ salt and P2VP samples). This is consistent with the formation of $\mathrm{Cu}^{0}$ and the associated reduction in the electron mean free path in $\mathrm{Cu}^{0}$ when compared to oxidised $\mathrm{Cu}^{43}$.

Following anneal the $\mathrm{O} 1 \mathrm{~s}$ peak (figure $2 \mathrm{~b}$ ) in both samples is significantly reduced in intensity. As figure 5 shows, annealing results in the formation of metallic $\mathrm{Cu}$, which explains the reduction in not only the copper oxide $\mathrm{O} 1 \mathrm{~s}$ components, but also the $\mathrm{SiO}_{2}$, due to a metal layer being present above the material. For the salt annealed sample, C-O bonds make up a significant portion of the fit, suggesting that an $\mathrm{O}$ rich $\mathrm{C}$ film remains on the sample. The oxide annealed sample is dominated by the $\mathrm{SiO}_{2}$ signal, and unlike the salt annealed sample, there is little evidence of $\mathrm{C}-\mathrm{O}$ bonding, as most of the $\mathrm{C}$ had been removed prior to the oxidation step. Another aspect of the fit is the component located at $530.2 \mathrm{eV}$. This was fitted with a narrower Gaussian contribution than the other oxygen components, and is associated with an oxygen component in metallic copper $\left(\mathrm{Cu}^{0} \mathrm{O}\right)$. This feature becomes evident in the annealed salt- 
infiltrated sample due to the presence of $\mathrm{Cu}^{0}$, and rises in intensity in the annealed oxide sample, which has a more clearly defined $\mathrm{Cu}^{0}$ signal.

A significant decrease in intensity of the $C 1 s$ is observed when annealing the $\mathrm{Cu}$ salt sample, with only small signals of $\mathrm{C}-\mathrm{C}$ and $\mathrm{C}-\mathrm{O}$ bonds. This fact, combined with the removal of all $\mathrm{N}$ signals, shows that the polymer layer has been removed by the anneal. The analysis in the previous section for the $\mathrm{Cu}$ oxide sample revealed that only small signals in the $\mathrm{C} 1 \mathrm{~s}$ signal remained after the oxidation step. Following the anneal however, these trace elements are desorbed. The small signals from the $\mathrm{N} 1 \mathrm{~s}$ signal were also no longer observed after the anneal.

Annealing both samples resulted in the $\mathrm{Cu} 2 p_{3 / 2}$ spectra (figure $5 \mathrm{a}$ ) losing the shake-up features seen in the spectra of both the $\mathrm{Cu}$ salt and $\mathrm{Cu}$ oxide samples, with the maxima of the doublets shifting to a lower binding energy. The fit shows that the anneal has converted both samples from oxide into metallic copper, with only a small component of $\mathrm{Cu}^{1+}$ remaining. It should be noted however that the intensity of the $\mathrm{Cu}^{0}$ signal is significantly larger in the annealed copper oxide sample. This is significant, since it potentially shows that, although annealing both the salt-infiltrated and the oxidised samples yields the same result, a greater amount of $\mathrm{Cu}^{0}$ remains on the annealed $\mathrm{Cu}$ oxide sample, indicating the possible importance of the oxidation step. This increase in intensity is also seen in the annealed $\mathrm{Cu} 1 \mathrm{~s}$ spectra (figure $5 \mathrm{~b}$ ), supporting the conclusions drawn from figure 5 a.

\section{Discussion}

The photoemission and EDX data provides important information regarding the chemical interactions that occur in the metal salt inclusion process. Every critical core level at each stage of the process has been fitted robustly, with the peak fitting parameters carefully obtained. The HAXPES data shows that, once the metal salt solution is spun onto the polymer, the $\mathrm{Cu}$ undergoes a strong chemical interaction with the $\mathrm{N}$ in the pyridine ring, with the detection of a $\mathrm{N}-\mathrm{Cu}$ bonding component in the $\mathrm{N} 1 s, \mathrm{Cu} 2 p$ and $\mathrm{Cu} 1 s$ core levels. The EDX mapping data supports these conclusions, showing that thin films of the polymer pre- and post-metal salt infiltration can be acquired. The UV/Ozone process converts the salt-infiltrated film into a pure copper oxide layer. The removal of the polymer is evident from EDX mapping and the lack of $C$ 1s and $\mathrm{N} 1 \mathrm{~s}$ core levels in the photoemission spectra. Annealing the copper oxide layer produces $\mathrm{Cu}^{0}$ on the surface, demonstrating that both insulating dielectric materials and conducting films can be fabricated using this approach.

\section{Conclusions}

Significant progress is being made in developing future polymer ASD processes for nanoelectronic device fabrication. The study reported here provides a detailed understanding of a novel ASD process. A starting polymer has been analysed, successfully infiltrated and subsequently fabricated to copper oxide and metallic copper respectively. The work has proven that by using this wet chemistry technique, P2VP polymer films can be created, infiltrated with metal salts, and used to create metals and metal oxides. This demonstrates that P2VP can be used for high-k dielectrics and metallic nanoelectronic device fabrication via ASD for large scale CMOS using a number of processing steps. In order for further advancements in ASD, it is essential to assess the chemical environment of fabricated materials. Using HAXPES 
measurements we have shown that it is possible to analyse in detail the chemical environment of each species present throughout the range of experimental steps, thereby obtaining a full understanding of the surface chemistry that underpins the infiltration, oxidation, and reduction processes of the technique. In addition, the study is beneficial for technologies that utilise pyridine containing BCP's.

\section{Acknowledgments}

The authors would like to thank SOLEIL Synchrotron for the use of their facilities in making the experimental measurements as well as the support given by the beamline scientists (SOLEIL proposal number 20180106). Special thanks to Jennifer McKenna, Matt Shaw, Alan Bell, Christopher O'Neill and David Bird at Intel Ireland, Leixlip. P.G. Mani-Gonzalez would like to acknowledge CONACYT for the funding of the sabbatical year 2018-000007-01EXTV-00235. This publication has emanated from research conducted with the financial support of Science Foundation Ireland (SFI) under grant number 12/RC/2278 and 16/SP/3809

\section{References}

1. Segalman, R. A. Patterning with block copolymer thin films. Materials Science and Engineering: R: Reports 48, 191-226 (2005).

2. Hawker, C. J. \& Russell, T. P. Block Copolymer Lithography: Merging “Bottom-Up" with “TopDown" Processes. MRS Bulletin 30, 952-966 (2005).

3. Pandey, K., Ghosh, K., Manna, U. \& Biswas, M. Block Copolymer Templated Fabrication of $\mathrm{TiO}_{2}$ Nanodot Films Using Pulsed Laser Deposition. The Journal of Physical Chemistry C 122, 16325-16332 (2018).

4. Tseng, Y.-C. \& Darling, S. B. Block Copolymer Nanostructures for Technology. Polymers 2, 470-489 (2010).

5. Borah, D. et al. Plasma etch technologies for the development of ultra-small feature size transistor devices. Journal of Physics D: Applied Physics 44, 174012 (2011). 
6. Peng, Q., Tseng, Y.-C., Darling, S. B. \& Elam, J. W. Nanoscopic Patterned Materials with Tunable Dimensions via Atomic Layer Deposition on Block Copolymers. Advanced Materials 22, 5129-5133 (2010).

7. Kamcev, J. et al. Chemically Enhancing Block Copolymers for Block-Selective Synthesis of SelfAssembled Metal Oxide Nanostructures. ACS Nano 7, 339-346 (2013).

8. Cummins, C., Bell, A. P. \& Morris, M. A. Creating Active Device Materials for Nanoelectronics Using Block Copolymer Lithography. Nanomaterials (Basel) 7, (2017).

9. Varghese, J. et al. Fabrication of Arrays of Lead Zirconate Titanate (PZT) Nanodots via Block Copolymer Self-Assembly. Chemistry of Materials 25, 1458-1463 (2013).

10. Cummins, C. \& Morris, M. A. Using block copolymers as infiltration sites for development of future nanoelectronic devices: Achievements, barriers, and opportunities. Microelectronic Engineering 195, 74-85 (2018).

11. Cummins, C., Shaw, M. T. \& Morris, M. A. Area Selective Polymer Brush Deposition. Macromolecular Rapid Communications 38, 1700252 (2017).

12. Cho, D., Noro, A., Takano, A. \& Matsushita, Y. TGIC Separation of PS- $b$-P2VP Diblock and P2VP- $b$-PS- $b$-P2VP Triblock Copolymers According to Chemical Composition. Macromolecules 38, 3033-3036 (2005).

13. Rueff, J.-P. et al. The GALAXIES beamline at the SOLEIL synchrotron: inelastic X-ray scattering and photoelectron spectroscopy in the hard X-ray range. Journal of Synchrotron Radiation 22, 175-179 (2015). 
14. Herrera-Gomez, A., Bravo-Sanchez, M., Ceballos-Sanchez, O. \& Vazquez-Lepe, M. O. Practical methods for background subtraction in photoemission spectra. Surface and Interface Analysis 46, 897-905 (2014).

15. Himpsel, F. J., McFeely, F. R., Taleb-Ibrahimi, A., Yarmoff, J. A. \& Hollinger, G. Microscopic structure of the SiO 2 /Si interface. Physical Review B 38, 6084-6096 (1988).

16. Herrera-Gomez, A. et al. Structure of Ultra-Thin Diamond-Like Carbon Films Grown with Filtered Cathodic Arc on Si(001). Analytical sciences : the international journal of the Japan Society for Analytical Chemistry 26, 267-72 (2010).

17. Thøgersen, A., Selj, J. H. \& Marstein, E. S. Oxidation effects on graded porous silicon anti-reflection coatings. J. Electrochem. Soc. 159, D276-D281 (2012).

18. Strauß, F. et al. Li-Si thin films for battery applications produced by ion-beam cosputtering. RSC Advances 5, 7192-7195 (2015).

19. Wright, K. \& Barron, A. Catalyst Residue and Oxygen Species Inhibition of the Formation of Hexahapto-Metal Complexes of Group 6 Metals on Single-Walled Carbon Nanotubes. C 3, 17 (2017).

20. Menapace, I., Yiming, W. \& Masad, E. Chemical analysis of surface and bulk of asphalt binders aged with accelerated weathering tester and standard aging methods. Fuel 202, 366-379 (2017).

21. Sun, X., Liu, H. T. \& Cheng, H. F. Oxidation behavior of silicon nitride fibers obtained from polycarbosilane fibers via electron beam irradiation curing. RSC Adv. 7, 47833-47839 (2017). 
22. Tien, H.-W., Huang, Y.-L., Yang, S.-Y., Wang, J.-Y. \& Ma, C.-C. M. The production of graphene nanosheets decorated with silver nanoparticles for use in transparent, conductive films. Carbon 49, 1550-1560 (2011).

23. Morelos-Gómez, A. et al. Controlling the Optical, Electrical and Chemical Properties of Carbon Inverse Opal by Nitrogen Doping. Advanced Functional Materials 24, 2612-2619 (2014).

24. Nesov, S. N., Korusenko, P. M., Bolotov, V. V., Povoroznyuk, S. N. \& Smirnov, D. A. Electronic structure of nitrogen-containing carbon nanotubes irradiated with argon ions: XPS and XANES studies. Physics of the Solid State 59, 2030-2035 (2017).

25. Gabka, G. et al. Ligand exchange in quaternary alloyed nanocrystals - a spectroscopic study. Phys. Chem. Chem. Phys. 16, 23082-23088 (2014).

26. Barber, M. et al. Bonding in some donor-acceptor complexes involving boron trifluoride. Study by means of ESCA and molecular orbital calculations. J. Chem. Soc., Faraday Trans. 2 69, 551-558 (1973).

27. Calderon-Ayala, G. et al. Green synthesis of reduced graphene oxide using ball milling. Carbon letters 21, 93-97 (2017).

28. Liu, Y. et al. Nitrogen-Doped Single-Walled Carbon Nanotubes Grown on Substrates: Evidence for Framework Doping and Their Enhanced Properties. Advanced Functional Materials 21, 986-992 (2011). 
29. Susi, T., Pichler, T. \& Ayala, P. X-ray photoelectron spectroscopy of graphitic carbon nanomaterials doped with heteroatoms. Beilstein Journal of Nanotechnology 6, 177-192 (2015).

30. Biesinger, M. C. Advanced analysis of copper X-ray photoelectron spectra: Advanced analysis of copper X-ray photoelectron spectra. Surface and Interface Analysis 49, 13251334 (2017).

31. Chavez, K. L. \& Hess, D. W. A Novel Method of Etching Copper Oxide Using Acetic Acid. Journal of The Electrochemical Society 148, G640 (2001).

32. Handy, J. V., Ayala, G. \& Pike, R. D. Structural comparison of copper(II) thiocyanate pyridine complexes. Inorganica Chimica Acta 456, 64-75 (2017).

33. Gordon, P. G., Kurek, A. \& Barry, S. T. Trends in Copper Precursor Development for CVD and ALD Applications. ECS Journal of Solid State Science and Technology 4, N3188-N3197 (2015).

34. Wagner, A. J., Wolfe, G. M. \& Fairbrother, D. H. Reactivity of vapor-deposited metal atoms with nitrogen-containing polymers and organic surfaces studied by in situ XPS. Applied Surface Science 219, 317-328 (2003).

35. Liu, Z. Q., Wang, W. J., Wang, T. M., Chao, S. \& Zheng, S. K. Thermal stability of copper nitride films prepared by rf magnetron sputtering. Thin Solid Films 325, 55-59 (1998).

36. Kim, N. Y. et al. Diffusion of copper into polyimide deposited by ionized cluster beam. Journal of Vacuum Science \& Technology B: Microelectronics and Nanometer Structures 17, 380 (1999). 
37. Pels, J. R., Kapteijn, F., Moulijn, J. A., Zhu, Q. \& Thomas, K. M. Evolution of nitrogen functionalities in carbonaceous materials during pyrolysis. Carbon 33, 1641-1653 (1995).

38. Biesinger, M. C. et al. Resolving surface chemical states in XPS analysis of first row transition metals, oxides and hydroxides: $\mathrm{Cr}, \mathrm{Mn}, \mathrm{Fe}, \mathrm{Co}$ and $\mathrm{Ni}$. Applied Surface Science 257, 2717-2730 (2011).

39. Biesinger, M. C., Payne, B. P., Lau, L. W. M., Gerson, A. \& Smart, R. St. C. X-ray photoelectron spectroscopic chemical state quantification of mixed nickel metal, oxide and hydroxide systems. Surface and Interface Analysis 41, 324-332 (2009).

40. Grosvenor, A. P., Kobe, B. A., Biesinger, M. C. \& Mclntyre, N. S. Investigation of multiplet splitting of Fe $2 p$ XPS spectra and bonding in iron compounds. Surface and Interface Analysis 36, 1564-1574 (2004).

41. Biesinger, M. C., Brown, C., Mycroft, J. R., Davidson, R. D. \& Mclntyre, N. S. X-ray photoelectron spectroscopy studies of chromium compounds. Surface and Interface Analysis 36, 1550-1563 (2004).

42. Pratt, A. R., Mclntyre, N. S. \& Splinter, S. J. Deconvolution of pyrite, marcasite and arsenopyrite XPS spectra using the maximum entropy method. Surface Science 396, 266272 (1998).

43. Lesiak, B., Jablonski, A., Zemek, J. \& Jiricek, P. Determination of the inelastic mean free paths of electrons in copper and copper oxides by elastic peak electron spectroscopy (EPES). Surface and Interface Analysis 26, 400-411 (1998). 
